\title{
MAPEAMENTO DE CONHECIMENTO NA PLATAFORMA SCOPUS: UM ESTUDO SOBRE A INDÚSTRIA CRIATIVA
}

\author{
KNOWLEDGE MAPPING ON SCOPUS:
} A STUDY ON THE CREATIVE INDUSTRY

\begin{abstract}
Cristiano Max Pereira Pinheiro ${ }^{1}$
Mauricio Barth ${ }^{2}$

Serje Schmidt ${ }^{3}$

Dusan Schreiber ${ }^{4}$

\section{RESUMO}

Buscando destacar o momento oportuno à compreensão do tema, este trabalho visa apresentar um mapeamento da produção científica no domínio da Indústria Criativa, através de uma proposta de mineração de textos científicos na base de dados Scopus, fundamentada em métodos bibliométricos. Para o desenvolvimento teórico da pesquisa, são utilizados autores como Howkins (2002), Deheinzelin (2011), Reis (2012), Prodanov e Freitas (2013), Hauenstein (2008), Vanti (2006), M. Hayashi, Faria e C. Hayashi (2013). Ao fim do estudo, destaca-se que, através dos critérios estabelecidos, o levantamento realizado apontou 933 publicações na área de Indústria Criativa. Ressalta-se, ainda, outros resultados quantitativos são analisados como as seguintes categorias com maior número de publicações: ano (2013), periódico (International Journal of Cultural Policy), autor (C. Gibson), instituição de ensino (Queensland University), país (Reino Unido) e área de assunto (Ciências Sociais).

PALAVRAS-CHAVE: Indústria criativa. Bibliometria. Scopus.

ABSTRACT: Seeking to highlight the appropriate time to understand the issue, this paper presents a mapping of scientific production in the field of Creative Industries, through a proposed mining of scientific texts in the Scopus database, based on bibliometric methods. For the theoretical development of research, authors like Howkins (2002), Deheinzelin (2011), Reis (2012), Prodanov and Freitas (2013), Hauenstein (2008), Vanti (2006), M. Hayashi, Faria and C. Hayashi (2013) are used. At the end of the study, it is emphasized that through the established criteria, the survey showed 933 publications in the area of Creative Industries. It is noteworthy also other quantitative results are as the following categories with the highest number of publications: year (2013), journal (International Journal of Cultural Policy), author (C. Gibson), School (Queensland University), country (UK) and subject area (Social Sciences).
\end{abstract}

KEYWORDS: Creative Industry. Bibliometrics. Scopus.

\footnotetext{
${ }^{1}$ Doutorado em Comunicação Social; coordenador dos Cursos de Jornalismo, Relações Públicas e Publicidade e Propaganda e professor do Mestrado em Indústria Criativa da Universidade Feevale/RS. E-mail: mauricio@feevale.br

${ }^{2}$ Mestrado em Indústria Criativa na Universidade Feevale/RS; bolsista de Desenvolvimento Tecnológico Industrial do CNPq. E-mail: maxrs@ feevale.br

3 Doutorado em Administração (Unisinos) e Economía de L'empresa (Universitat de Les Illes Balears); professor do Mestrado em Indústria Criativa da Universidade Feevale/RS. E-mail: serje@feevale.br

${ }^{4}$ Doutorado em Administração (UFRGS); coordenador do Mestrado em Indústria Criativa da Universidade Feevale/RS. E-mail: dusan@feevale.br
}

Recebido em: 06/06/2014 - Aceito em: 26/03/2015 


\section{INTRODUÇÃO}

A Indústria Criativa vem atraindo olhares nos mais diversos meios, de forma mais contundente, nas dimensões acadêmicas e governamentais (REIS, 2012). Do ponto de vista universitário, pode-se destacar a criação de inúmeros cursos voltados à área, incluindo atividades de extensão e cursos em nível de pós-graduação strictu sensu ${ }^{5}$. Sob o prisma governamental, evidencia-se a criação, em 2012, da SEC - Secretaria de Economia Criativa, do Ministério da Cultura -, que surge como iniciativa impulsionadora do setor ${ }^{6}$.

Dessa forma, buscando destacar o momento oportuno à compreensão do tema, o objetivo deste trabalho é apresentar um mapeamento da produção científica no domínio da Indústria Criativa, através de uma proposta de mineração de textos científicos na base de dados Scopus, fundamentada em métodos bibliométricos. Tais resultados buscam demonstrar, quantitativamente, o movimento de publicações na área, observando os seguintes aspectos: ano, título de periódico, autor, instituição de origem, país e área de assunto. Cabe salientar que o levantamento quantitativo não desqualifica $o$ potencial de relevância da individualidade; é, apenas, uma forma de retratar um momento no cenário científico contemporâneo das pesquisas.

O presente estudo estrutura-se da seguinte forma: após a introdução, na seção 2, disserta-se sobre a Indústria Criativa, buscando fundamentar seu conceito. Para isso, utilizarse-ão autores como Howkins (2002), Deheinzelin (2011), Reis (2012), Bendassolli et al. (2009), Nicolaci-da-Costa (2011) e Valiati (2013). Na sequência, a seção 3 visa demonstrar o método que permitiu aos pesquisadores chegar aos resultados pretendidos pelo estudo. São citados autores como Prodanov e Freitas (2013), Hauenstein (2008), Vanti (2006), M. Hayashi, Faria e C. Hayashi (2013), Araujo (2006), Meneghini e Packer (2008), Lu e Wolfram (2010) e Machado (2007). A seção 4, busca evidenciar os resultados da pesquisa, destacando, através de gráficos demonstrativos, o corpus proposto para este estudo. Por fim, encerra-se esta pesquisa com as considerações finais e as referências utilizadas.

A seguir, na seção 2, discorre-se sobre os termos e definições que cercam a Indústria Criativa.

\section{INDÚSTRIA CRIATIVA}

No fim dos anos 1990, o Departamento de Cultura, Mídia e Esportes (DCMS) do Reino Unido lançou um mapeamento da Indústria Criativa, cunhando, assim, um novo conceito, demonstrando que determinadas empresas podem ir além de seu papel cultural e podem, de maneiras mercadológicas, gerar valores consideráveis (HOWKINS, 2002).

\footnotetext{
${ }^{5}$ PORTAL INTERCOM. Universidade Feevale oferecerá o primeiro mestrado em Indústria Criativa do país. Disponível em:

<http://www.portalintercom.org.br/index.php?option=com_content \&view=article \&id=4395\&Itemid=138>. Acesso em: 01 mai. 2014.

${ }^{6}$ SEC. Secretaria da Economia Criativa. Disponível em: <http://www.cultura.gov.br/secretaria-da-economiacriativa-sec>. Acesso em: 01 mai. 2014.
} 
Deheinzelin (2011) define a Indústria Criativa como uma economia baseada em recursos intangíveis, já que sua principal matéria-prima é a ideia. Para a autora, nunca chegaremos, inclusive, a uma real definição da área e estaremos, sempre, em uma "versão Beta". Contudo, não possuir um conceito definitivo e absoluto pode, de alguma forma, ser benéfico pois, neste caso, cada local adequa-se à significação que mais lhe convém (REIS, 2012).

Apresenta-se, a seguir, o Quadro 1, que ilustra alguns entendimentos sobre o conceito de Indústria Criativa.

QUADRO 1 - Definições de Indústria Criativa

\begin{tabular}{|c|c|}
\hline DEFINIÇÃO & REFERÊNCIAS \\
\hline $\begin{array}{l}\text { "Atividades que têm a sua origem na criatividade, competências e talento individual, } \\
\text { com potencial para a criação de trabalho e riqueza por meio da geração e exploração } \\
\text { de propriedade intelectual [...] As indústrias criativas têm por base indivíduos com } \\
\text { capacidades criativas e artísticas, em aliança com gestores e profissionais da área } \\
\text { tecnológica, que fazem produtos vendáveis e cujo valor econômico reside nas suas } \\
\text { propriedades culturais (ou intelectuais)." }\end{array}$ & DCMS (2005, p. 5) \\
\hline $\begin{array}{l}\text { "A ideia de indústrias criativas busca descrever a convergência conceitual e prática das } \\
\text { artes criativas (talento individual) com as indústrias culturais (escala de massa), no } \\
\text { contexto de novas tecnologias midiáticas (TIs) e no escopo de uma nova economia do } \\
\text { conhecimento, tendo em vista seu uso por parte de novos consumidores cidadãos } \\
\text { interativos." }\end{array}$ & Hartley $(2005$, p. 5) \\
\hline $\begin{array}{l}\text { "Em minha perspectiva, é mais coerente restringir o termo 'indústria criativa' a uma } \\
\text { indústria onde o trabalho intelectual é preponderante e onde o resultado alcançado é a } \\
\text { propriedade intelectual." }\end{array}$ & $\begin{array}{l}\text { Howkins }(2005, \mathrm{p} . \\
119)\end{array}$ \\
\hline $\begin{array}{l}\text { "As indústrias criativas são formadas a partir da convergência entre as indústrias de } \\
\text { mídia e informação e o setor cultural e das artes, tornando-se uma importante (e } \\
\text { contestada) arena de desenvolvimento nas sociedades baseadas no conhecimento [...] } \\
\text { operando em importantes dimensões contemporâneas da produção e do consumo } \\
\text { cultural [...] o setor das indústrias criativas apresenta uma grande variedade de } \\
\text { atividades que, no entanto, possuem seu núcleo na criatividade." }\end{array}$ & $\begin{array}{l}\text { Jeffcutt }(2000, p . \\
123-124)\end{array}$ \\
\hline $\begin{array}{l}\text { "As atividades das indústrias criativas podem ser localizadas em um continuum que } \\
\text { vai desde aquelas atividades totalmente dependentes do ato de levar o conteúdo à } \\
\text { audiência (a maior parte das apresentações ao vivo e exibições, incluindo festivais) que } \\
\text { tendem a ser trabalho-intensivas e, em geral, subsidiadas, até aquelas atividades } \\
\text { informacionais orientadas mais comercialmente, baseadas na reprodução de conteúdo } \\
\text { original e sua transmissão a audiências (em geral distantes) (publicação, música } \\
\text { gravada, filme, broadcasting, nova mídia)." }\end{array}$ & $\begin{array}{l}\text { Cornford e Charles } \\
(2001, \text { p. } 17)\end{array}$ \\
\hline
\end{tabular}

Fonte: Bendassolli et al. (2009, p. 12)

Como visto no quadro 1, embora os conceitos tenham inúmeras redações, há um elemento central em destaque: a criatividade; é através dela que, conforme Simonton (2000), novos negócios surgem e a economia pode avançar em sentidos exponenciais. Para Nicolaci- 
da-Costa (2011), a criatividade é o componente-chave para a difusão dos negócios do futuro, atraindo olhares dos mais diversos campos.

Assim como, ainda, não há uma definição clara do conceito, há, também, imprecisões nas áreas que compõem a Indústria Criativa (REIS, 2012). O quadro a seguir demonstra os modelos comumente usados, como o Modelo do DCMS, o Modelo de Textos Simbólicos, o Modelo de Círculos Concêntricos e o Modelo de Direitos Autorais.

QUADRO 2 - Sistemas de classificação para as indústrias criativas derivados dos diferentes modelos internacionais

\begin{tabular}{|c|c|c|c|}
\hline $\begin{array}{c}\text { MODELO DO } \\
\text { DEPARTAMENTO DE } \\
\text { CULTURA, MÍDIA E } \\
\text { ESPORTE DO REINO } \\
\text { UNIDO } \\
\end{array}$ & $\begin{array}{l}\text { MODELO DE TEXTOS } \\
\text { SIMBÓLICOS }\end{array}$ & $\begin{array}{l}\text { MODELO DE CÍRCULOS } \\
\text { CONCÊNTRICOS }\end{array}$ & $\begin{array}{l}\text { MODELO DE DIREITOS } \\
\text { AUTORAIS }\end{array}$ \\
\hline \multirow{4}{*}{$\begin{array}{l}\text { Publicidade } \\
\text { Arquitetura } \\
\text { Mercado de arte e } \\
\text { antiguidades } \\
\text { Artesanato } \\
\text { Design } \\
\text { Moda } \\
\text { Filme e vídeo } \\
\text { Música } \\
\text { Artes cênicas } \\
\text { Publicação } \\
\text { Software } \\
\text { Televisão e rádio } \\
\text { Videogames e jogos para } \\
\text { computador }\end{array}$} & $\begin{array}{l}\text { Núcleo das indústrias } \\
\text { culturais } \\
\text { Publicidade } \\
\text { Filme } \\
\text { Internet } \\
\text { Música } \\
\text { Publicação } \\
\text { Televisão e rádio } \\
\text { Videogames e jogos para } \\
\text { computador }\end{array}$ & $\begin{array}{l}\text { Núcleo das artes criativas } \\
\text { Literatura } \\
\text { Música } \\
\text { Artes cênicas } \\
\text { Artes visuais }\end{array}$ & $\begin{array}{l}\text { Núcleo das indústrias de } \\
\text { direitos autorais } \\
\text { Publicidade } \\
\text { Associações de } \\
\text { colecionadores } \\
\text { Filme e vídeo } \\
\text { Música } \\
\text { Artes cênicas } \\
\text { Publicação } \\
\text { Software } \\
\text { Televisão e rádio } \\
\text { Arte gráfica e visual }\end{array}$ \\
\hline & $\begin{array}{l}\text { Indústrias culturais } \\
\text { periféricas } \\
\text { Artes criativas }\end{array}$ & $\begin{array}{l}\text { Outros núcleos das } \\
\text { indústrias culturais } \\
\text { Filme } \\
\text { Museus e bibliotecas }\end{array}$ & $\begin{array}{l}\text { Indústrias de direitos } \\
\text { autorais interdependentes } \\
\text { Material de gravação em } \\
\text { branco } \\
\text { Eletrônicos de consumo } \\
\text { Instrumentos musicais } \\
\text { Papel } \\
\text { Fotocopiadoras, } \\
\text { equipamento fotográfico }\end{array}$ \\
\hline & \multirow[t]{2}{*}{$\begin{array}{l}\text { Indústrias culturais de } \\
\text { fronteira } \\
\text { Eletrônicos de consumo } \\
\text { Moda } \\
\text { Software } \\
\text { Esporte }\end{array}$} & $\begin{array}{l}\text { Indústrias culturais mais } \\
\text { amplas } \\
\text { Serviços de preservação da } \\
\text { herança cultural } \\
\text { Publicação } \\
\text { Gravação de som } \\
\text { Televisão e rádio } \\
\text { Videogames e jogos para } \\
\text { computador }\end{array}$ & \multirow[t]{2}{*}{$\begin{array}{l}\text { Indústrias de direitos } \\
\text { autorais parciais } \\
\text { Arquitetura } \\
\text { Vestuário, calçados } \\
\text { Design } \\
\text { Moda } \\
\text { Artigos domésticos } \\
\text { Brinquedos }\end{array}$} \\
\hline & & $\begin{array}{l}\text { Indústrias relacionadas } \\
\text { Publicidade } \\
\text { Arquitetura } \\
\text { Design } \\
\text { Moda }\end{array}$ & \\
\hline
\end{tabular}

Fonte: Valiati (2013, p. 11)

Percebe-se, através do quadro exposto, que há áreas que se repetem nos diferentes modelos, como, por exemplo, Publicidade, Música e Filmes. Contudo, há segmentos 
exclusivos de determinados sistemas, como o Esporte, localizado, apenas, no Modelo de Textos Simbólicos. Isso ocorre pela diferença cultural nas diversas dimensões que ela afeta, como sociedade e governo; ou, ainda, pelas especificidades e potenciais mercadológicos de determinadas regiões, fazendo com que os conceitos flexibilizem a necessidade de um norteamento filosófico nacional.

O fato é que, embora sua prática já exista a algum tempo, o debate em torno da Indústria Criativa é, relativamente, recente. Sendo assim, conforme Chapain e Comunian (2011), não cabe - pelo menos nesses primeiros momentos - uma discussão acirrada buscando consolidar um modelo definitivo; basta, apenas, deixar que o tempo se encarregue de estabelecer uma definição mais concreta.

A seção seguinte objetiva demonstrar os métodos utilizados neste trabalho.

\section{PROCEDIMENTOS METODOLÓGICOS}

A presente seção tem por objetivo apresentar o percurso metodológico a ser trilhado para a realização deste trabalho. Segundo Prodanov e Freitas (2013), o método científico é um conjunto de procedimentos adotados como propósito de atingir o conhecimento. De acordo com Hauenstein (2008), o método científico é um traço característico da ciência, constituindo-se em instrumento básico que ordena, inicialmente, o pensamento em sistemas e traça os procedimentos do cientista ao longo do caminho até atingir o objetivo científico preestabelecido. O método é, também, a ordem que se deve impor aos diferentes processos necessários para atingir um fim dado ou um resultado que é desejado (TACHIZAWA; MENDES, 2006).

Este estudo, metodologicamente, utiliza um levantamento quantitativo associado a uma pesquisa bibliométrica. Segundo Vanti (2006), a bibliometria é um instrumento estatístico que permite mapear e determinar díspares apontadores de tratamento e gestão do conhecimento e da informação, sobretudo, em sistemas de comunicação e informação tecnológicos e científicos. Trata-se de uma forma concreta de mapear o conhecimento produzido e, a partir disto, o pesquisador tem autonomia para analisar seus dados e produzir as considerações pertinentes (HAYASHI, M.; FARIA; HAYASHI, C., 2013; ARAUJO, 2006).

Sendo assim, o percurso metodológico adotado para a realização desta pesquisa buscou artigos vinculados ao tema "Indústria Criativa" na base de dados eletrônica Scopus ${ }^{7}$ que, por sua abrangência e importância, permite inferências consistentes sobre o assunto. Como trata-se de uma plataforma internacional, o termo objeto de estudo foi pesquisado em inglês, buscando, sobretudo, resultados que direcionassem a uma produção em nível mundial.

\footnotetext{
7 Justifica-se a escolha da base Scopus por ser considerada hoje a maior base de dados multidisciplinar de resumos, citações e textos completos da literatura científica mundial, lançada pela Editora Elsevier, em 2004 (OLIVEIRA; GRÁCIO, 2012). Jacso (2005) afirma que a Scopus encontra-se, juntamente com o Google Scholar e a Web of Science, entre as maiores bases de dados multidisciplinares.
} 
A escolha do termo-filtro para a pesquisa foi determinada considerando fatores como: a) a amplitude de estudos que se pretendia alcançar; b) a diferenciação da área de conhecimento entre economia criativa e indústria criativa; c) e a necessidade de utilização do termo entre aspas, para não incorrer em materiais que possuíssem as palavras sem o contexto semântico necessário.

Assim sendo, para a coleta dos dados, pesquisou-se na referida base de dados o termo "Creative Industry" (entre aspas) no campo principal de busca ${ }^{8}$. Assinalou-se a opção Article Title, Abstract, Keywords (o termo pesquisado constando no título, no resumo ou nas palavras-chave'), All years to Present no campo Published (publicações ocorridas em qualquer ano), All no campo Document Type (qualquer tipo de documento, desde artigos científicos completos até resumos) e, em Subject Areas, optou-se em deixar todas as opções assinaladas (preferiu-se, desse modo, contemplar todas as áreas de estudo possíveis pela plataforma). A figura a seguir ilustra o processo de busca.

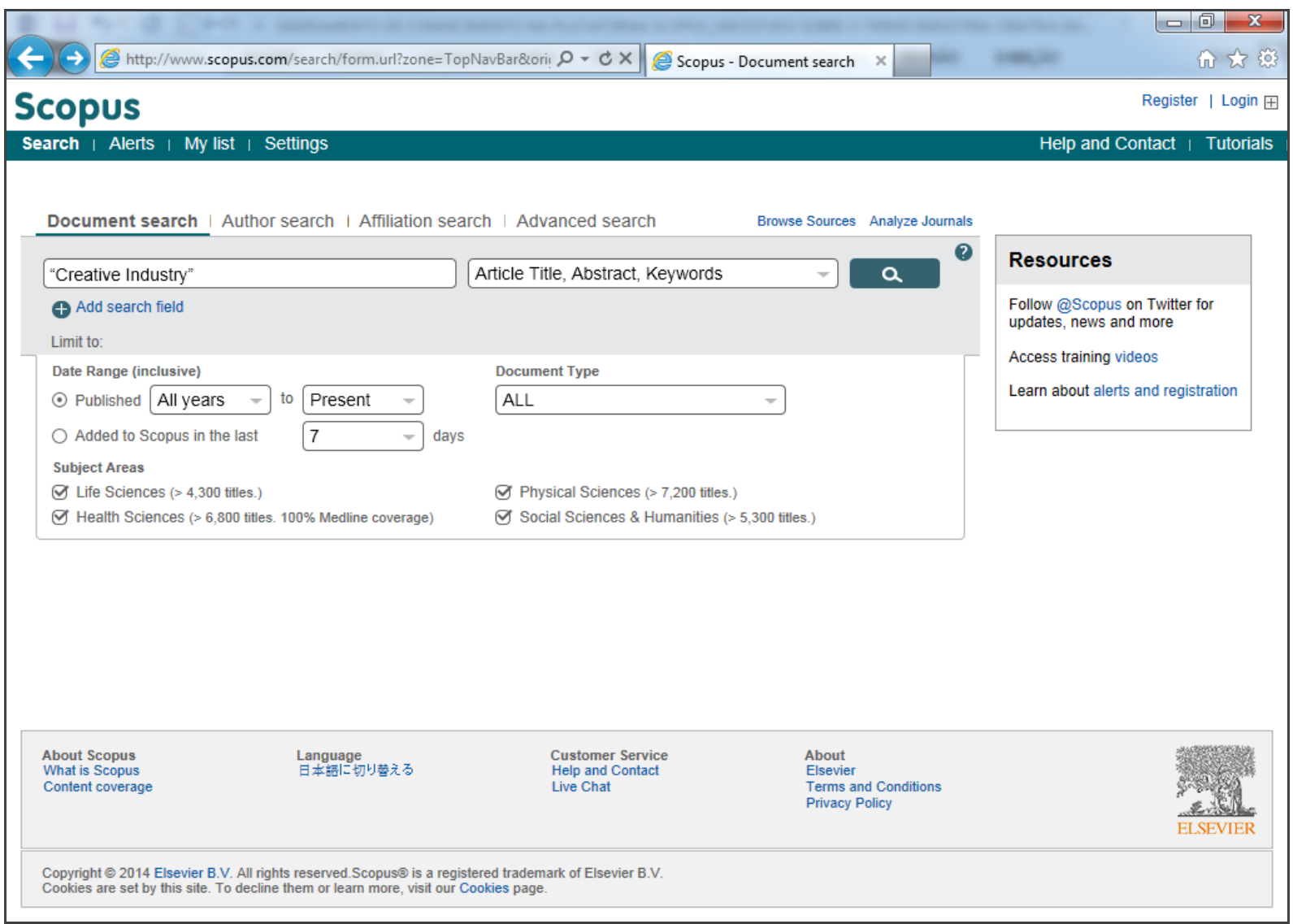

FIGURA 1 - Coleta dos dados do termo "Creative Industry"

Fonte: Capturado pelos pesquisadores (SCOPUS, 2014, online)

A seção seguinte apresenta os resultados do mapeamento bibliométrico realizado.

\footnotetext{
${ }^{8}$ A seleção do termo de busca contempla os termos presentes na metodologia adotada por Meneghini e Packer (2008), Lu e Wolfram (2010) e Machado (2007).

${ }^{9}$ Este critério foi selecionado pelos autores por acreditarem que, assim, o Scopus filtra trabalhos que tratam, essencialmente, de Indústria Criativa.
} 


\section{RESULTADOS}

A pesquisa, que consistia em examinar o termo "Creative Industry" em todos os itens possíveis de busca, apontou, em 01 de maio de 2014, 993 resultados. O gráfico ${ }^{10}$ a seguir demonstra a publicação anual de trabalhos vinculados ao tema. Percebe-se que, em 2013, o número de publicações atingiu seu auge, com o número de 184 produções. O crescimento significativo da produção científica sobre a Indústria Criativa reflete o momento atual da área que, anualmente, vem ganhando grande exposição, conforme mencionado, anteriormente, por Reis (2012).

Nota-se, contudo, dois picos que geram uma oscilação entre os anos de 2011 e 2012. Alguns fatos podem estar potencializando os auges de 2010 e 2013; esses são, respectivamente, anos de lançamento de Relatórios das Nações Unidas sobre o cenário Mundial (UNCTAD, 2010; UNCTAD, 2013). Consultores acadêmicos são contratados para auxiliar nos relatórios e o material gerado pode provocar um aumento de publicações naqueles anos, afora a curva de aumento natural. Em 2010, ocorre, também, o lançamento do Mestrado em Gestão de Indústrias Criativas da Universidade Católica do Porto, em Portugal, demonstrando a tendência que as Instituições de Ensino Superior possuem na oferta de formação científica para o campo.

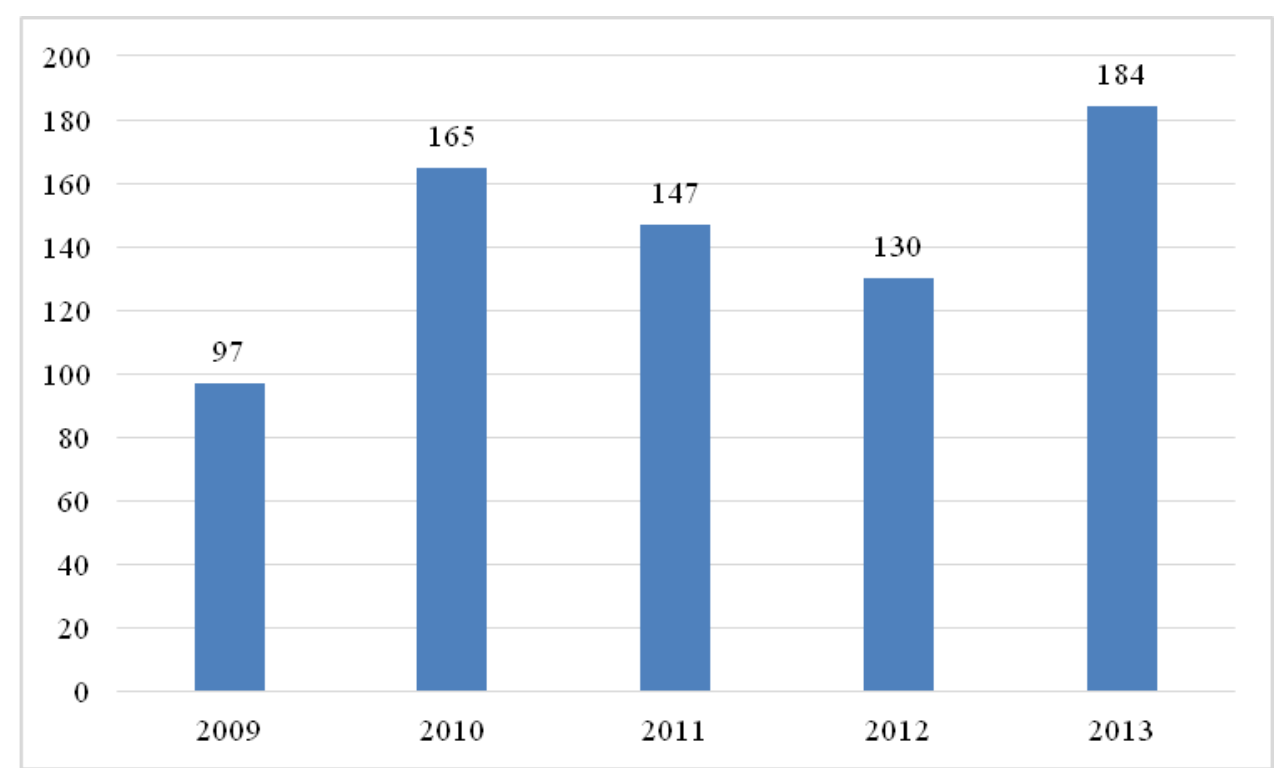

GRÁFICO 1 - Número de publicações anuais

Fonte: Elaborado pelos pesquisadores

À seguir, demonstram-se os títulos dos periódicos com maior número de produções relativas à Indústria Criativa. Destacam-se International Journal of Cultural Policy (23), International Journal of Cultural Studies (19), Lecture Notes in Computer Science (19), Creative Industries Journal (18) e Taiwan Review (14). Segundo Tachizawa e Mendes (2006), a utilização de revistas e periódicos científicos é de fundamental importância para a

\footnotetext{
${ }^{10}$ A fim de facilitar a sua compreensão, os gráficos elaborados pelos pesquisadores demonstram apenas os cinco primeiros colocados no ranking da respectiva categoria. Tal forma de apresentação é recomendada por Gil (2012) e Prodanov e Freitas (2013).
} 
formação de um qualificado pesquisador, pois, através disso, o mesmo passa a ter contato com a escrita técnico-científica de alto impacto. Cabe salientar que, até o momento de finalização deste trabalho, nenhuma das revistas a seguir possui avalição no Sistema WebQualis da Capes ${ }^{11}$.

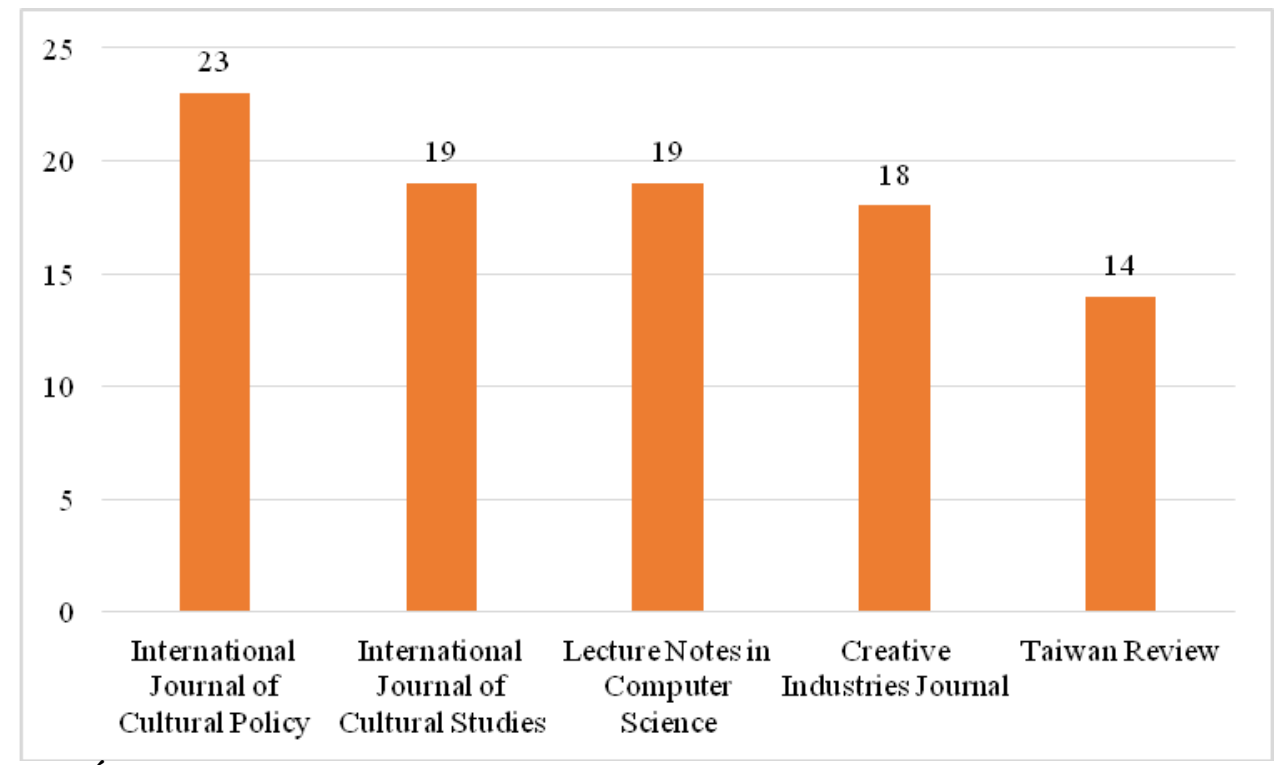

GRÁFICO 2 - Título da publicação e seu número de produções

Fonte: Elaborado pelos pesquisadores

Quanto aos autores que mais publicaram, destacam-se: a) Chris Gibson (15 produções), Professor da Universidade de Wollongong na Austrália, originalmente do campo da Geografia; b) Stuart Cunningham (10 produções), Professor da Universidade de Tecnologia de Queensland na Austrália, originalmente do campo da Comunicação; c) Jason Potts (8 produções), Professor da Universidade RMIT na Austrália, originalmente do campo da Economia; d) Rungtai Lin (7 produções), Professor da Universidade Nacional de Artes de Taiwan, originalmente do campo do Design; e) Terry Flew (7 produções), Professor da Universidade de Tecnologia de Queensland, originalmente do campo da Comunicação. Destaca-se, oportunamente, que o ramo cientifico é composto, em sua maioria, por autores que demonstram grande produtibilidade, contribuindo, assim, para o progresso da área científica (HAUENSTEIN, 2008; TACHIZAWA; MENDES, 2006).

${ }^{11}$ Disponível em: <http://qualis.capes.gov.br/webqualis/principal.seam>. 


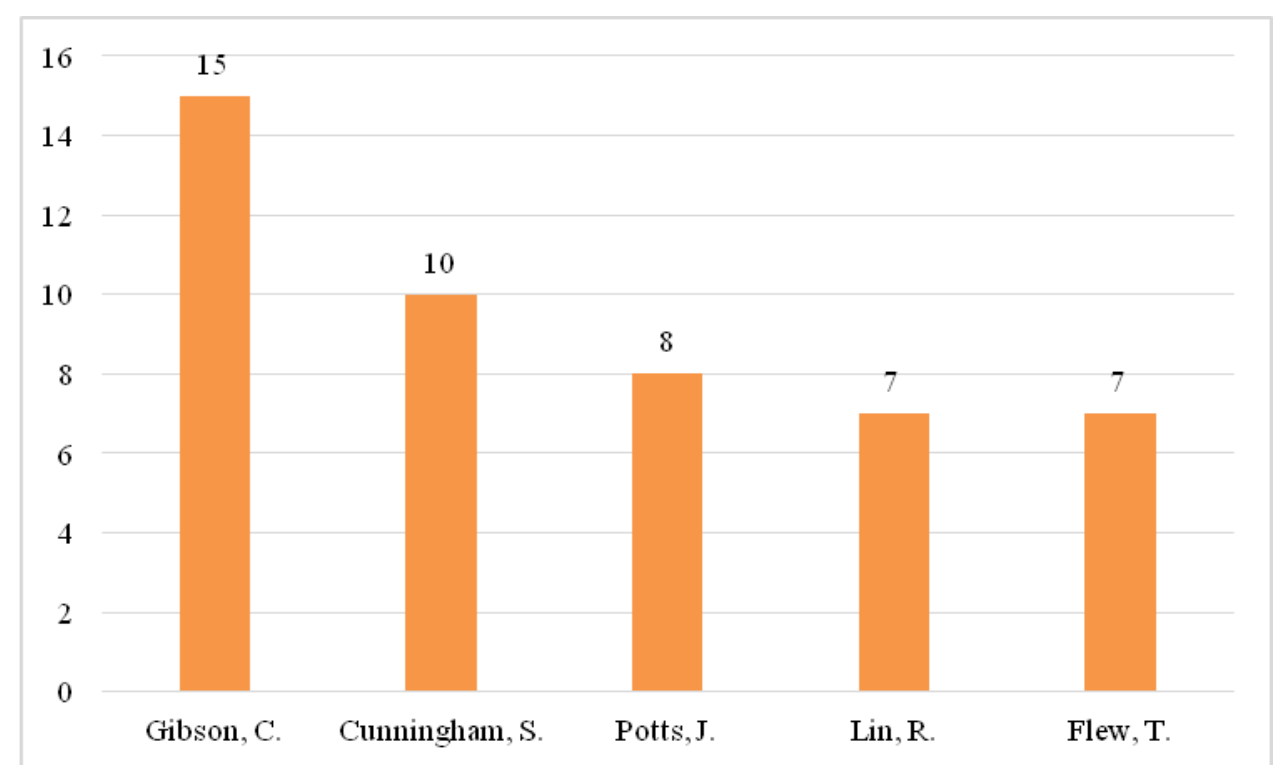

GRÁFICO 3 - Nome do autor e seu número de publicações

Fonte: Elaborado pelos pesquisadores

No que diz respeito às Instituições de Ensino Superior que mais produziram trabalhos relacionados à Indústria Criativa, podemos citar a Queensland University (57 publicações), com uma significativa diferença em relação a segunda colocada, a University of Wollongong (15 publicações). Após, temos Vilniaus Gedimino technikos universitetas (13 publicações), Copenhagen Business School (12 publicações) e University of Queensland (12 publicações). Consolidar-se como um grande polo de publicações pode, de muitas formas, fortalecer a imagem da Instituição como promotora de conhecimento cientifico (VALIATI, 2013).

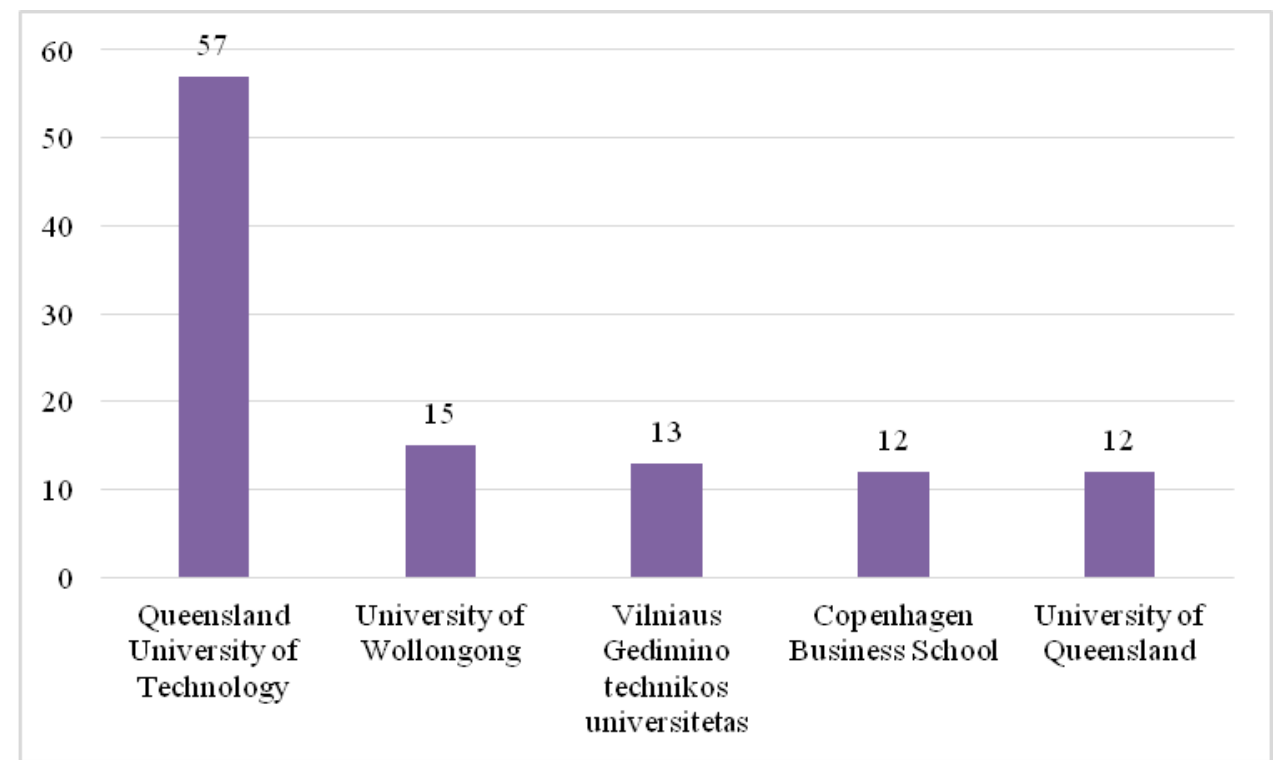

GRÁFICO 4 - Instituição de origem e seu número de publicações

Fonte: Elaborado pelos pesquisadores

A figura a seguir demonstra os países que mais produziram publicações sugestivas à Indústria Criativa. No topo, estão o Reino Unido (206 produções), seguido por Austrália (140 produções), China (117 produções), Estados Unidos (77 produções) e Taiwan (73 produções). Destaca-se, sobretudo, a supremacia inglesa, que possui um número significativo em relação 
ao segundo colocado. O Reino Unido, para Howkins (2002), percebeu, ao longo dos anos, a real influência que a Indústria Criativa possui em um mercado globalizado, onde a criatividade tende a ser um fator determinante em segmentos comerciais fortemente competitivos.

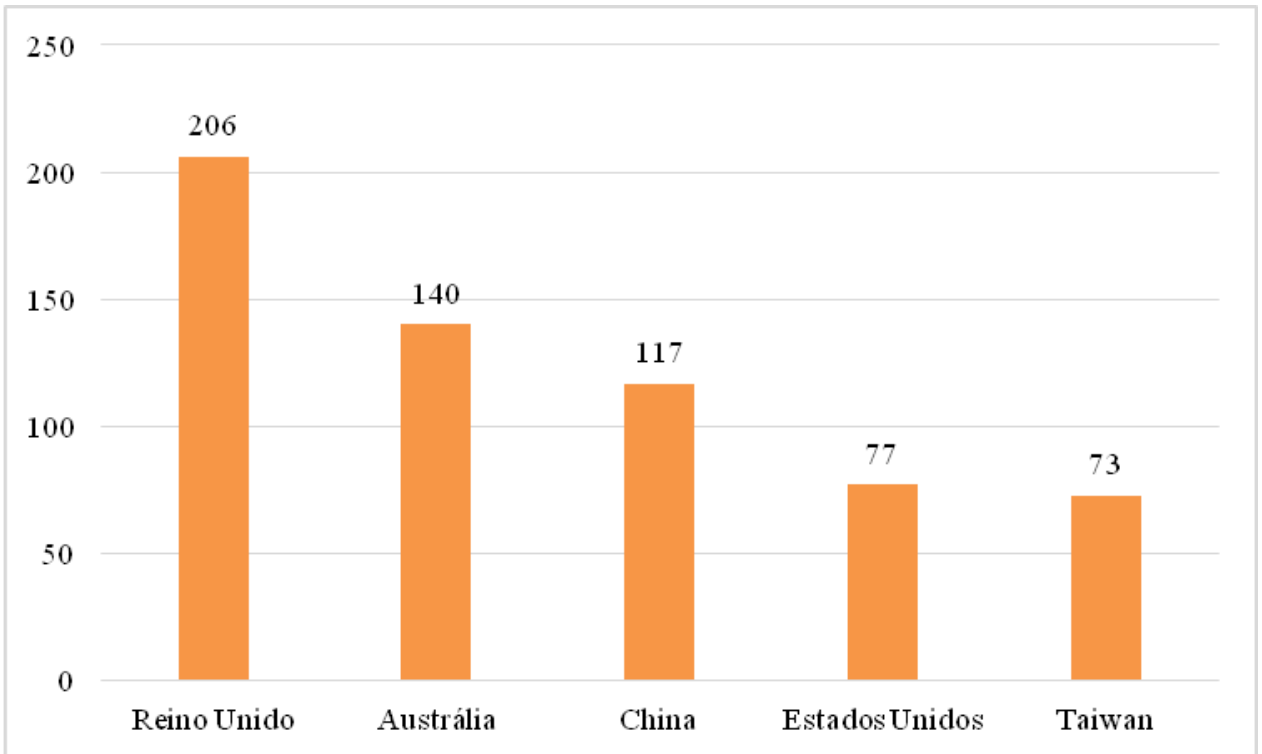

GRÁFICO 5 - País de origem e seu número de publicações

Fonte: Elaborado pelos pesquisadores

No que tange às áreas que mais produzem estudos vinculados à Indústria Criativa, destacam-se os segmentos de Ciências Sociais (532), Negócios, Gestão e Ciências Contábeis (286), Ciências Computacionais (159), Artes e Humanas (141) e Engenharia (119). Chapain e Comunian (2011) destacam a importância da Indústria Criativa justamente pelo fato da mesma transitar em diferentes áreas, trilhando, assim, caminhos em segmentos variados e proporcionando aos mesmos relevantes trocas de experiências.

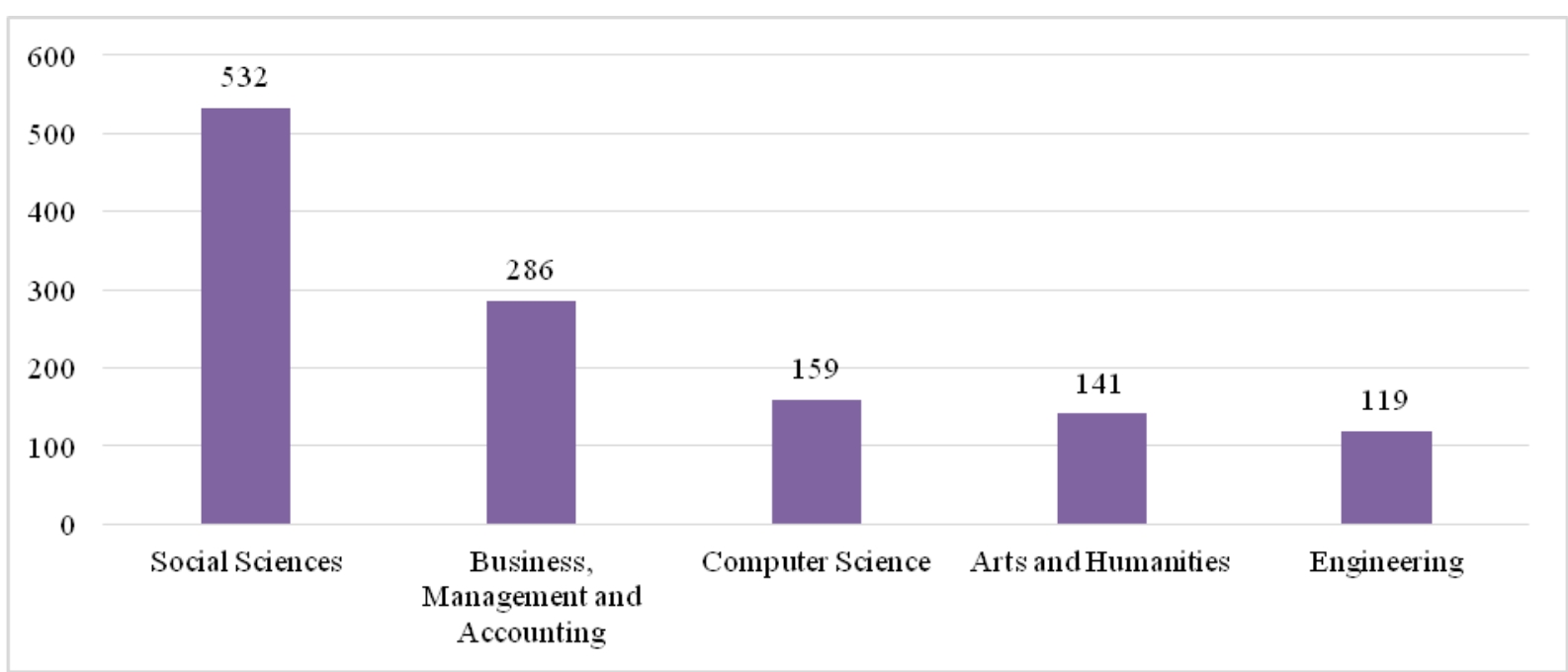

GRÁFICO 6 - Área de conhecimento e seu número de publicações

Fonte: Elaborado pelos pesquisadores 
O quadro-síntese a seguir demonstra, dentre os itens abordados pela pesquisa, quais são aqueles que, quantitativamente, obtiveram maior relevância, bem como algumas observações sobre cada um dos líderes do ranking.

QUADRO 3 - Quadro-síntese dos resultados

\begin{tabular}{|l|c|l|l|}
\hline \multicolumn{5}{|c|}{ Destaques quantitativos da busca sobre o termo "Creative Industry" } \\
\hline Ano & 2013 & 184 publicações & $\begin{array}{l}\text { Este ano é o auge das publicações sobre Indústria } \\
\text { Criativa e uma demonstração de que a produção de } \\
\text { conhecimento sobre a área cresce ano após ano. }\end{array}$ \\
\hline Periódico & $\begin{array}{c}\text { International } \\
\text { Journal of } \\
\text { Cultural Policy }\end{array}$ & 23 publicações & $\begin{array}{l}\text { Periódico acadêmico com cobertura } \\
\text { interdisciplinar, cujo escopo disserta sobre } \\
\text { questões como o significado, a função e o impacto } \\
\text { das políticas culturais. }\end{array}$ \\
\hline Autor & C. Gibson & 15 publicações & $\begin{array}{l}\text { Professor da Universidade de Wollongong } \\
\text { Austrália) e consagrado autor de obras que } \\
\text { envolvem discussões acerca da Indústria Criativa. }\end{array}$ \\
\hline Ensino Superior & Uneensland & 57 publicações & $\begin{array}{l}\text { Universidade australiana sediada em Brisbane e } \\
\text { fundada em 1909. É considerada, atualmente, uma } \\
\text { das cinco melhores universidades australianas em } \\
\text { pesquisa intensiva. }\end{array}$ \\
\hline País & Reino Unido & 206 publicações & $\begin{array}{l}\text { Através do Departamento de Cultura, Mídia e } \\
\text { Esportes (DCMS) o Reino Unido lançou um } \\
\text { mapeamento da Indústria Criativa, cunhando, } \\
\text { assim, um novo conceito, demonstrando a grande } \\
\text { importância que o país possui na área. }\end{array}$ \\
\hline Área & Ciências Sociais & 532 publicações & $\begin{array}{l}\text { As Ciências Sociais estão vinculadas a diversos } \\
\text { segmentos pertencentes às áreas que compõem a } \\
\text { Indústria Criativa. }\end{array}$ \\
\hline
\end{tabular}

Fonte: Elaborado pelos pesquisadores

Na sequência, apresentam-se as considerações finais deste estudo.

\section{CONSIDERAÇÕES FINAIS}

Este estudo buscou apresentar um mapeamento da produção científica no domínio da Indústria Criativa, através de uma proposta de mineração de textos científicos na base de dados Scopus, abalizada em métodos bibliométricos. Seu escopo era demonstrar, quantitativamente, o movimento de publicações na área, observando os seguintes aspectos: ano, título de periódico, autor, instituição de origem, país e área de assunto.

Ao fim do trabalho, constata-se que, quanto ao ano, as publicações na área de Indústria Criativa atingiram seu auge em 2013, com 184 publicações. Quanto ao título do periódico, destaca-se o International Journal of Cultural Policy, com 23 publicações. No que tange aos autores que mais publicaram, destaca-se C. Gibson, com 15 produções. Já no que diz respeito às Instituições de Ensino Superior que mais produziram trabalhos vinculados à 
Indústria Criativa, podemos citar a Queensland University, com 57 publicações e uma significativa diferença em relação a segunda colocada, a University of Wollongong (15 publicações). No topo da lista dos países que mais produziram publicações referentes à Indústria Criativa, está o Reino Unido (206 produções). Por fim, ao relacionar-se as áreas que mais produziram estudos vinculados à Indústria Criativa, destaca-se o segmento de Ciências Sociais, com 532 publicações.

Após os resultados expostos, pode-se, de forma mais tangível, perceber a produção de conhecimento que cerca a Indústria Criativa, já que, de posse do mapeamento realizado, os pesquisadores tem um maior entendimento sobre a elaboração do material científico produzido na área. Inclusive, como sugestão de novos estudos, pode-se ampliar o número de bases utilizadas, não atendo-se somente ao Scopus, mas, sim, utilizando plataformas como Proquest $^{12}$, Google Scholar ${ }^{13}$ e/ou Web of Sciences ${ }^{14}$. Há, ainda, a possibilidade de vincular ao termo Indústria Criativa as áreas que a compõem, como Publicidade, Design, Moda, Arquitetura, entre outras.

\section{REFERÊNCIAS}

ARAUJO, C. A. A. Bibliometria: evolução histórica e questões atuais. Em Questão, Porto Alegre, v. 12, n.1, jan./jun., 2006, p. 11-32.

BENDASSOLLI, P. F. et al. Indústrias criativas: definição, limites e possibilidades. RAE, São Paulo, v. 49, n.1, jan./mar. 2009.

BOHANNON, J. Google Scholar wins raves - but can it be trusted? Scientific publishing, New York, v. 343, 2014.

CHAPAIN, C.; COMUNIAN, R. Dynamics and differences across creative industries in the UK: exploring the case of Birmingham. Redige, v. 2, n. 02, aug. 2011.

DEHEINZELIN, L. Economia Criativa e métodos para dar uma mão ao futuro. Redige, v. 2, n. 02, ago. 2011.

ENIS, M. ProQuest launches LIS Education Program. Library Journal, v. 137, fasc. 15, 2012.

GARCIA-PEREZ, M. Accuracy and completeness of publication and citation records in the Web of Science, PsycINFO, and Google Scholar: A case study for the computation of $h$ indices in Psychology. Journal of the American Society for Information Science and Technology, v. 61, fasc. 10, 2010.

\footnotetext{
${ }^{12}$ Base de dados que fornece arquivos de fontes, tais como jornais, periódicos, dissertações e bancos de dados agregados de muitos tipos. Seu conteúdo é estimado em 125 bilhões de páginas digitais (ENIS, 2012).

${ }^{13}$ Ferramenta de pesquisa do Google que permite pesquisar em trabalhos acadêmicos, literatura escolar, jornais de universidades e artigos variados (BOHANNON, 2014).

${ }^{14}$ Bases de dados que faz referência à investigação interdisciplinar, que permite a exploração em profundidade de subcampos especializados dentro de uma disciplina acadêmica ou científica (GARCIA-PEREZ, 2010).
} 
GIL, A. C. Metodologia do ensino superior. 4. ed. São Paulo, SP: Atlas, 2012.

GRÁCIO, M. C. C.; OLIVEIRA, E. F. T. de. Visibilidade dos pesquisadores no periódico Scientometrics a partir da perspectiva brasileira: um estudo de cocitação. Em Questão, Porto Alegre, v. 18, Edição Especial, p. 99-113, dez. 2012.

HAYASHI, M. C. P. I.; FARIA, L. I. L. de; HAYASHI, C. R. M. Bibliometria e cientometria: estudos temáticos. São Carlos, SP: Pedro \& João Editores, 2013. 333 p.

HOWKINS, J. The Creativy Economy: How People make Money from Ideas. EUA: Penguin Books, 2002.

JACSO, P. As we may search - Comparison of major features of the Web of Science, Scopus and Google Scholar citation-based and citation-enhanced databases. Current Science, v. 89, n. 9, p. 1537-1547, nov. 2005.

LU, K.; WOLFRAM, D. Geographic characteristics of the growth of informetrics literature 1987-2008. Journal of Informetrics, v. 4, p. 591-601, 2010.

MACHADO, R. N. Análise cientométrica dos estudos bibliométricos publicados em periódicos da área de biblioteconomia e ciência da informação (1990-2005). Perspectivas em Ciência da Informação, v. 12, n.3, p.2-20, set./dez. 2007.

MENEGHINI, R.; PACKER, A. L. The extent of multidisciplinary authorship of articles on scientometrics and bibliometrics in Brazil. Interciencia, v.35, n. 7, p. 510-514, 2010.

NICOLACI-DA-COSTA, A. M. O talento jovem, a internet e o mercado de trabalho da “economia criativa". Psicologia \& Sociedade, v. 23, p. 554-563, 2011.

REIS, A. C. F. Cidades Criativas - da Teoria À Prática. São Paulo: Sesi, 2012.

SIMONTON, D. K. Creativity: Cognitive, Personal, Developmental, and Social Aspects. American Psycholgist, v. 55, n. 1, p. 151-158, 2000.

UNESCO. Creative economy report. 2010. Disponível em: <http://unctad.org/es/Docs/ditctab20103_en.pdf >. Acesso em: 01 jun. 2014.

UNESCO. Creative economy report. 2013. Disponível em: <http://www.unesco.org/culture/pdf/creative-economy-report-2013.pdf $>$. Acesso em: 01 jun. 2014.

VALIATI, L. Indústria criativa no Rio Grande do Sul: síntese teórica e evidências empíricas. Porto Alegre: FEE, 2013.

VANTI, N. A. P. Métodos quantitativos para a avaliação do fluxo da informação e do conhecimento: bibliometria, cientometria e informetria. Comunicação e informação: ensaios e críticas. Porto Alegre: Sulina, 2006. 
Como citar este documento:

PINHEIRO, Cristiano Max Pereira et al. Mapeamento de conhecimento na plataforma Scopus: um estudo sobre a indústria criativa.Revista Digital de Biblioteconomia e Ciência da Informação, Campinas, SP, v. 13, n. 2, p. 329-341, maio/ago 2015. ISSN 1678-765X. Disponível em: 〈http://periodicos.bc.unicamp.br/ojs/index.php/rdbci/article/view/8635336>. Acesso em: 31 maio 2015. 